We wish to express our indebtedness to Col. W. B. Stevenson, Commanding Officer of a General Hospital, and to Lt.-Col. G. I. Scott, Adviser in Ophthalmology, Middle East Forces, for their permission to publish this report.

\title{
REFERENCES
}

Feigenbaum, A., Michaelson, I. C. and Kornbluth, W.-Brit. Jl. Ophthal., Vol: XXIX, August, 1945.

Ridos, A.-Arch. Ophthal., Vol. XXXII, p. 308, October, 1944. (Review and full bibliography of epidemic kerato-con junctivitis).

Sanyal, S.-Amer. Jl. Ophthal., Vol. XXVI, p. 390, 1933.

VIsWALINGaM, A.-Brit. Jl. Ophthal., Vol. XXV, p. 313, 1941.

\section{THE USE OF CRYSTALLINE PENICILLIN IN CORNEAL AND INTRA-OCULAR INFECTION*}

\author{
Frank JULER and G. T. JOHNSON \\ ST. MARY'S HOSPITAL, LONDON, W.2
}

IN a recent review of the literature concerning the use of penicillin in ophthalmology, Rycroft (1945) makes no mention of the direct application of the undissolved salt to the surface of the eyeball. Sorsby (1945) in a similar review does just mention the method, in referring to a paper by. Juler and Young (1945) on infective corneal ulcer, but in a recent annotation in the Brit. Med.Jl. (1946) entitled "Penicillin in Ophthalmology" no mention is made of this procedure.

From practical clinical experience we feel that this method is worth emphasis, as affording the maximum concentration of the drug in relation to the infection itself.

The method was suggested to one of us (F. A. J.) by Professor Ida Mann (personal communication, February, 1944) who wrote as follows :- "In a small child with a large corneal abscess an incision was made and some crystals of penicillin were put into the cavity. This was repeated twice a day for three days and, although the cornea perforated it healed completely without synechiae and with a scar which was only slightly opaque."

In the report by Juler and Young (1945) the method was described after an extensive trial, chiefly in senile patients with severe corneal lesions.

In that series it was found that the instillation of drops on the cornea did not suffice in the more heavily infected cases, especially in persons of marked senility, and especially, where hypopyon was

\footnotetext{
- Received for publication, February 11, 1946.
} 
associated with secondary glaucoma. In that series the crystalline salt was applied in 12 of these more severe cases; in 6 of these there was no evidence of secondary glaucoma, and no further spread of ulceration; in the other six cases, the ocular tension was increased, further spread occurred in four of these, and a Saemisch section was necessary; after this healing occurred without further spread, and no eye had to be excised.

It has now been used in a number of infective processes and some case reports are given below.

In spite of the impurity of the present penicillin products, no harm seems to have accrued to the human eye from the applications of crystals to a surface ulceration or to an open wound, with the following exception :-

In a case of hypopyon ulcer associated with post-herpetic anaesthesia of the cornea some further loss of epithelial surface followed the application, but under a temporary lid suture, repair was soon made good, the infection having been stopped.

The infective processes which have derived benefit are as follows :-

Infective ulceration of the cornea, the deep recurrences of rosacea keratitis, infections through the filtration scar of a trephine operation, infections of perforating wounds and intra-ocular operations.

The crystals used have been those of sodium penicillinate. After instillation of decicain and (if thought necessary) orbital injection with 4 per cent. procaine, a minute amount is applied to the infected area, allowed to stand and dissolve, the while it is gently rubbed into the tissues. It is important to emphasise that it be rubbed well under any advancing edge of ulceration, and into any infiltration.

Pain is variable and sometimes severe. Up to date we have not repeated the applications more frequently than on alternate days, but as in Ida Mann's case, it may be possible to use it at shorter intervals.

Experimental work on aqueous content of penicillin, quoted by Rycroft (1945) and Sorsby (1945), has shown that in the absence of corneal epithelium penetration of the drug into the anterior chamber does occur from surface drops. It would seem reasonable to assume, therefore, that through a thin trephine bleb or an open wound a valuable concentration into the aqueous fluid would occur from crystalline application to the surface.

Whether such a diffusion takes place into the vitreous from a similar application, is a matter for further research. If it can be shown to occur the method will be less damaging to the eye than the introduction of fluid penicillin by means of a syringe into the vitreous body itself, which has been shown to be definitely harmful.

The following case reports seem worthy of record :- 
Case 1.-Mrs. H. N., a housewife, aged 50 years, was seen in the Out-patient Department with a central corneal ulceration of approximately $3 \mathrm{~mm}$. diameter and a small hypopyon. Vision was C.F. at $\frac{1}{2}$ metre.

The following day she was admitted to hospital and as much solid sodium penicillin as could be balanced on the grooved end of a silver probe was applied to the ulcer of the cocainised eye. By means of an iris repositor the ulcer was carefully curetted, especial care being taken to rub the penicillin beneath the undermined advancing edge of ulceration; the solid penicillin dissolved rapidly.

One drop of 1 per cent. atropine was instilked and a pad and bandage applied for 6 hours. Afterwards 1 drop of solution of 500 O.U. of penicillin was instilled, hourly by day and two hourly by nightcare being exercised to place the drops on the top of the cornea with the patient looking down. Atropine 1 per cent. was instilled into the conjunctival sac thrice daily.

The following day a definite improvement was noted and a further advance of the ulcer arrested. On the 3rd day the hypopyon was cleared and the ulcer had begun to epithelialize. The patient was discharged on the 9 th day with the cornea firmly healed and the eye whitening.

CASE 2.-Mr. McR., an alcoholic, aged 52 years. This man's only eye, two days after an intracapsular lens extraction, became congested, with corneal oedema and much muco-purulent discharge, which contained staphylococcus aureus.

500 O.U. of penicillin in 0.5 c.c. of distilled water were injected into the anterior chamber, and a course of 25,000 O.U. of penicillin was commenced subcutaneously, at 3 hourly intervals for four days.

Within 12 hours the eye was definitely worse and there was a complete hypopyon; the next day crystals of solid penicillin were applied under the conjunctival flap. A definite improvement was noted the next day when the application was repeated. Two days later, a paracentesis of the anterior chamber was performed, to diminish the raised intra-ocular tension. Eight days from the first application of penicillin crystals the eye began to whiten.

When the patient was discharged a fortnight later he had $4 / 60$ vision and was able to read J.10 with +10.D.Sph. Six months later he had $6 / 9$ with suitable correction.

CASE 3.-J. S., aged 34 years, had a hypopyon ulcer treated elsewhere with local applications' of penicillin drops and penicillin systemically; despite treatment the whole anterior layers of his cornea necrosed.

The same routine of treatment as in case 1 was repeated and within 24 hours a definite improvement was noted. Within 8 days his eye had begun to whiten and the hypopyon cleared completely. Unfortunately, the condition recurred within 3 weeks, possibly 
due to too early discharge from hospital; the whole eye became a suppurating mass, and subsequently had to be enucleated.

CASE 4.-J. S., aged 48 years, had a trephine operation three years previously for chronic glaucoma.

Ten days prior to admission to hospital his eye became inflamed and tender with the vision diminished to perception of light only. There was much exudate in the anterior chamber and a small hypopyon below. Bacteriological examination revealed infection with the staphylococcus aureus.

Solid penicillin was applied to the trephine bleb above, and the next day 500 units of penicillin in $\frac{1-}{2}$ c.c. of saline were placed in the anterior chamber. Conjunctivat penicillin drops were administered hourly by day and two hourly by night for 5 days.

The following day the hypopyon had diminished and the eye had begun to whiten but a remarkable feature was the exceptionally low ocular tension which was still observed when the patient was discharged from hospital after ten days, with his eye whitening and considerably improved.

When seen in the Out-patient Department later his eye was quiet and the vision was 6/24 partly, almost as good as 3 years previously after the trephining operation. The tension was inclined to be full.

CASE 5.-S. D. was an identical case to the one above,only with a diphtheroid infection, and was treated along exactly the same lines. Again-after the infection had begun to subside an exceedingly low ocular tension was noted but within one month it had returned to normal and the infection completely subsided.

The vision had returned to counting fingers at 1 metre, whereas previously it had been bare perception of light.

We have permission to copy a report by Professor Ida Mann to the Penicillin Trials Committee in 1944 as follows :-

" Eight eyes with corqeal ulcer were treated with penicillin ointment and in addition the surface of the ulcer was massaged with solid 290 unit penicillin applied with an iris repositor. Five healed with no other treatment. One only had hypopyon and had atropine in addition; this also healed. The remaining one' ( 2 eyes) was a case of Mooren's ulcer and showed no improvement.

In some of these cases the penicillin massage was applied several times at 24 hourly intervals ; in one case it was applied daily for eleven days, after which healing occurred "leaving a remarkably transparent scar."

\section{Summary}

Clinical experience in the application of crystals of penicillin to the cornea in infected ulcers, filtration scars and wounds is reported upon favourably. No evidence of harm to the tissues has been seen. Case records of typical cases are given. 


\title{
REFERENCES
}

JULER; Frank and Young, M. Y.-Brit. Jl. Ophthal., Vol. XXIX, p. 312, 1945. RYCROFT, B. W.-Brit. Jl. Ophthal., Vol. XXIX, p. 501, 1945. SorsBY, Ar Nold.-Brit. Jl. Ophthal., Voi. XXIX, p. 511, 1945. SorSBY, ARNOLD.-Brit. Med. Jl., January 16, 1946.

\section{ADDENDUM}

\section{The Use of Solid Penicillin in a Case of Endophthalmitis} following Lens Extraction

\section{BY}

$$
\text { D. Ainslie, M.B., B.Ch., D.O.M.S. }
$$

The patient was a man, aged 61 years, who underwent left lens extraction "on November 16,1945, at Moorfields Hospital.

The immediate post-operative course was uneventful, but the section did not close completely at first and gaped slightly for about ten days.

On the 8th day after the operation the cornea became hazy and a $3 \mathrm{~mm}$. hypopyon developed.

Solid penicillin powder (calcium salt) was applied to the line of the section, the total amount being about 20,000 units. The next day the hypopyon was reduced to $1 \mathrm{~mm}$. and the following day the cornea was again clear and there was no hypopyon.

Mild iritis persisted for about 10 days after which time the patient was discharged in a satisfactory condition, the eye being quiet, with normal tension, thickened capsule and good projection of light.

\section{AN OPERATION FOR POSTERIOR ROUTE EXTRACTION OF INTRA-OCULAR FOREIGN BODIES*}

\author{
BY \\ L. B. SOMERVILLE-LARGE \\ DUBLIN
}

RECENT ophthalmic literature has been flooded with the intra-ocular foreign body and its ramifications in relationship to ophthalmic war surgery. It would appear, however, from a study of the literature that the operative procedure for extraction by the posterior route has universally followed an approach advocated first, I think, by H. B. Stallard. The object of this article is to describe a method of posterior route extraction that I have been carrying out while in

- Received for publication, February 4, 1946. 


\title{
REFERENCES
}

JULER; Frank and Young, M. Y.-Brit. Jl. Ophthal., Vol. XXIX, p. 312, 1945. RYCROFT, B. W.-Brit. Jl. Ophthal., Vol. XXIX, p. 501, 1945. SorsBY, Ar Nold.-Brit. Jl. Ophthal., Voi. XXIX, p. 511, 1945. SorSBY, ARNOLD.-Brit. Med. Jl., January 16, 1946.

\section{ADDENDUM \\ The Use of Solid Penicillin in a Case of Endophthalmitis following Lens Extraction}

BY

D. Ainslie, M.B., B.Ch., D.O.M.S.

The patient was a man, aged 61 years, who underwent left lens extraction "on November 16,1945, at Moorfields Hospital.

The immediate post-operative course was uneventful, but the section did not close completely at first and gaped slightly for about ten days.

On the 8th day after the operation the cornea became hazy and a $3 \mathrm{~mm}$. hypopyon developed.

Solid penicillin powder (calcium salt) was applied to the line of the section, the total amount being about 20,000 units. The next day the hypopyon was reduced to $1 \mathrm{~mm}$. and the following day the cornea was again clear and there was no hypopyon.

Mild iritis persisted for about 10 days after which time the patient was discharged in a satisfactory condition, the eye being quiet; with normal tension, thickened capsule and good projection of light.

\section{AN OPERATION FOR POSTERIOR ROUTE EXTRACTION OF INTRA-OCULAR FOREIGN BODIES*}

\author{
BY \\ L. B. SOMERVILLE-LARGE \\ DUBLIN
}

RECENT ophthalmic literature has been flooded with the intra-ocular foreign body and its ramifications in relationship to ophthalmic war surgery. It would appear, however, from a study of the literature that the operative procedure for extraction by the posterior route has universally followed an approach advocated first, I think, by H. B. Stallard. The object of this article is to describe a method of posterior route extraction that I have been carrying out while in

- Received for publication, February 4, 1946. 